\title{
A review about biomarkers for the investigation of vascular function and impairment in diabetes mellitus
}

\author{
Giuseppe Derosa' \\ Pamela Maffioli ${ }^{2}$ \\ 'Centre of Diabetes and Metabolic \\ Diseases, Department of Internal \\ Medicine and Therapeutics, University \\ of Pavia and Fondazione IRCCS \\ Policlinico S. Matteo, ${ }^{2}$ School in \\ Experimental Medicine, University of \\ Pavia, Pavia, Italy
}

This article was published in the following Dove Press journal:

Vascular Health and Risk Management

9 November 2016

Number of times this article has been viewed
Abstract: The aim of this review was to analyze the main biomarkers of vascular function and impairment in patients with type 2 diabetes. Medline, SCOPUS, Web of Science, and Google Scholar databases were searched. We concluded that proatherogenic adhesion molecules (soluble intercellular adhesion molecule-1, soluble vascular adhesion molecule-1, and soluble E selectin) and inflammatory cytokines (high-sensitivity C-reactive protein, interleukin-6, and tumor necrosis factor- $\alpha$ ) were elevated in type 2 diabetes mellitus. Their increased expression and release contribute to the accelerated atherogenesis typical of these patients. For these reasons, the early identification of high levels of these biomarkers will help to establish new strategies to reduce cardiovascular complications.

Keywords: biomarkers, vascular function, type 2 diabetes mellitus

\section{Introduction}

Type 2 diabetes mellitus is responsible for high mortality rates, approximately twice that of the general population: micro- and macrovascular complications have been related to this disease. ${ }^{1}$ Several epidemiological studies showed a strong relationship between type 2 diabetes and cardiovascular events: ${ }^{2}$ diabetic patients have an incidence of triple vessel coronary artery disease or multivessel disease significantly higher compared to nondiabetics, and the severity of stenosis and total occlusion of vessels were more commonly seen in diabetic patients. ${ }^{3}$ This is because type 2 diabetes is involved and importantly implicated in the atherogenic process. ${ }^{4}$ Atherosclerosis is a well-known disease, where the progressive accumulation of cholesterol within the arterial wall plays the main role; this leads to the genesis of atheromatous plaques with consequent vascular narrowing. The rupture of these atheromatous plaques then leads to vascular occlusion, which may finally result in myocardial infarction, stroke, angina pectoris, or peripheral artery disease. ${ }^{5,6}$ Hyperglycemia, insulin resistance, hyperinsulinemia, hyperlipidemia (in particular elevated free fatty acids), and hyperhomocysteinemia are important pathophysiological components of type 2 diabetes mellitus that trigger systemic inflammation and impair nitric oxide (NO) bioavailability, with consequent impaired endothelial function. ${ }^{7}$

This review is aimed to analyze the biomarkers of vascular function and impairment in patients with type 2 diabetes; an early identification of these vascular abnormalities will allow study of new screening and therapeutic strategies in order to try to reduce the incidence of disease complications linked to atherosclerosis, especially in highrisk patients.
Correspondence: Giuseppe Derosa Diabetes and Metabolic Medicine and Therapeutics, University of Pavia and Fondazione IRCCS Policlinico S Matteo, P.le C. Golgi, 2, 27100 Pavia, Italy Tel +3938252 6217

Fax +39382526259

Email giuseppe.derosa@unipv.it 


\section{Mechanism of endothelial damage in patients with type 2 diabetes Hyperglycemia}

Hyperglycemia, in particular postprandial fluctuations, has been linked to endothelial dysfunction, and, combined with absolute increases in glycemia, contributes to oxidative stress and endothelial impairment. Oral glucose tolerance test is the best experimental technique to estimate pancreatic response to a standardized glucose oral load. Previous published studies reported that Oral Glucose Tolerance Test increased some biomarkers involved in inflammatory response and endothelial impairment, such as high-sensitivity C-reactive protein (Hs-CRP), interleukin-6 (IL-6), tumor necrosis factor- $\alpha$ (TNF- $\alpha$ ), soluble intercellular adhesion molecule-1 (sICAM-1), soluble vascular adhesion molecule-1 (sVCAM-1), and soluble E selectin (sE-selectin). ${ }^{8,9}$ Hyperglycemia enhances the secretion of endothelin-1, a vasoconstrictor, in vitro and decreases NO production in the aorta of diabetic rats and coronary microvessels in humans. Moreover, postprandial glycemia induces glycation of protein, which forms cross-linked proteins termed advanced glycation end products, with consequent synthesis and release of cytokines, vasoadhesion molecules, endothelin-1, and tissue factor.

\section{Insulin resistance and hyperinsulinemia}

Under physiologic conditions, other than the hypoglycemic function, insulin has also a hemodynamic action at the endothelial level promoting the release of the precapillary sphincter, inducing vasodilatation. ${ }^{10,11}$ To do this, insulin directly regulates expression and activation of NO synthase, inducing NO production by endothelial cells. Actually, insulin regulates both vasoconstrictor (endothelin-1) and vasodilator (NO) mediators; in euglycemic patients, the vasodilator effect of insulin prevails, while in insulin-resistant patients, endothelin-1 production is preserved, but NO synthesis is altered. ${ }^{11}$

\section{Hypertriglyceridemia}

Hypertriglyceridemia plays a role in the endothelial damage. We have already demonstrated in two previous studies we conducted that hypertriglyceridemia, in particular postprandial hypertriglyceridemia simulated by an oral fat load, is responsible for an elevated inflammatory state with an increase in metalloproteinase (MMP)-2 and MMP-9 and a decreased nitrites/nitrates ratio. ${ }^{12,13}$ The endothelial damage derived can cause an impaired release of smooth musculature endothelium-mediated, throughout an impaired release of NO. ${ }^{14}$

\section{Hyperhomocysteinemia}

Hyperhomocysteinemia is linked to cardiovascular diseases. ${ }^{15}$ Homocysteine is responsible for endothelial cell dysfunction and apoptosis of endothelial and smooth muscle cells involved in the atherothrombotic process. ${ }^{16}$ Homocysteine structure is characterized by a very reactive thiol group, easily oxidized to produce reactive oxygen species. ${ }^{17}$ On this basis, we can suppose that homocysteine induces cell dysfunction through autooxidation and oxidative damage. Moreover, homocysteine stimulates the production of several cytokines with proinflammatory action. ${ }^{18}$

\section{Microalbuminuria}

Microalbuminuria has been identified as a strong indicator of increased cardiovascular risk among patients with type 2 diabetes and also in patients without diabetes. Previous publications estimated that microalbuminuria causes a 2.4-fold increased risk for cardiovascular death compared to that in patients without microalbuminuria. ${ }^{19,20}$ If microalbuminuria is diagnosed, we must consider that cardiovascular risk is higher, and patient requires a more "aggressive" intervention for the prevention of cardiovascular events. ${ }^{21}$

\section{Inflammatory markers}

Inflammation plays a key role in the genesis and progression of atherosclerosis. In patients with type 2 diabetes, the inflammatory markers are higher than those in nondiabetic patients, as already shown in several studies. ${ }^{22}$

In particular, TNF- $\alpha$ is one of the main characters in the acute phase reaction. It is produced mainly by activated macrophages and also by monocytes, T-cells, smooth muscle cells, adipocytes, and fibroblasts. TNF- $\alpha$ has important proinflammatory properties and regulates the innate and adaptive immunity, cell proliferation, and apoptosis. ${ }^{23} \mathrm{TNF}-\alpha$ is also able to induce proatherogenic lipoprotein changes and to reduce insulin sensitivity. ${ }^{23}$

Another important inflammatory marker is Hs-CRP, mainly synthesized by hepatocytes; high levels reflect active systemic inflammation. The Multiple Risk Factor Intervention Trial, for example, was the first trial to show a strong link between high Hs-CRP and high mortality from coronary heart disease. ${ }^{24}$ These data were then confirmed by many other primary prevention, prospective epidemiological trials; in the area where ischemia and necrosis occurred, an increase in inflammatory cytokine has been reported. ${ }^{25}$ The increase in Hs-CRP seems linked to the extension of infarct and with increased possibility of cardiac rupture. ${ }^{26}$ 
On the other hand, myeloperoxidase (MPO) is a leukocyte-derived enzyme, it is the main protein in neutrophils, but it is also present in monocytes. MPO uses $\mathrm{H}_{2} \mathrm{O}_{2}$ to generate $\mathrm{HOCl}$, producing reactive oxidant species. ${ }^{27}$ Other than being a major character in the innate immune response, MPOderived oxidants contribute to tissue damage during inflammation and atherosclerosis. MPO activates protease cascades, including both proapoptotic and prothrombotic pathways, involved in plaque rupture, and intracoronary thrombus generation during sudden cardiac death. ${ }^{28,29}$ However, MPO is also involved in several inflammatory-mediated diseases. ${ }^{30}$

Increased levels of IL-6 have also been also linked to high risk of all-cause mortality. IL-6 is an important mediator in inflammation and has a central role for the acute-phase response. ${ }^{31} \mathrm{IL}-6$ is mostly produced by adipocytes, fibroblast, endothelial cells, and activated leukocytes and monocytes. IL-6 is a regulator of acute-phase inflammatory response; IL-6 stimulates the synthesis of C-reactive protein (CRP) by liver. ${ }^{32}$

Serum paraoxonase-1 (PON-1) is associated with high-density lipoprotein and prevents lipoproteins from oxidation. It has a hepatic synthesis and production. PON-1 has a protective action against atherosclerosis. PON-1 has antiatherogenic properties, linked to the enzyme's ability to prevent low-density lipoprotein (LDL) and high-density lipoprotein oxidation, to reduce macrophage oxidation, to stimulate cholesterol efflux from macrophages, and to reduce oxidative status in atherosclerotic plaques. PON-1 also destroys active lipids in mildly oxidized LDL, with a consequent reduction in inflammatory responses in the artery wall cells. PON-1 also reduces monocyte chemotaxis and adhesion to endothelial cells and inhibits monocyteto-macrophage differentiation. The absence of PON-1 was linked to an overexpression of adhesion molecules. ${ }^{33}$ LDL oxidation is the first step in atherosclerosis genesis. The oxidized products are scavenged by macrophages that transform into foam cells, filled with cholesterol esters. They eventually become fatty streaks in the endothelium. Lower PON activity was found in patients with type 2 diabetes with neuropathy and retinopathy. ${ }^{34,35}$

\section{Endothelial damage markers}

Endothelial dysfunction typical of diabetes plays a role in atherosclerotic lesions promoting the upregulation of adhesion molecules, the increase in chemokine secretion and leukocyte adherence, the increase in cell permeability, and an enhanced LDL oxidation, platelet activation, cytokine elaboration, and vascular smooth muscle cell proliferation and migration. ${ }^{36}$
Nitrate and nitrite are an alternative source for NO. Vasodilation, inhibition of endothelial dysfunction, and inhibition of platelet aggregation are protective mechanisms against cardiovascular diseases..$^{37} \mathrm{NO}$ mediates the regulation of vascular tone, with an increase in cyclic guanosine monophosphate and subsequent relaxation of vascular smooth muscle. NO suppresses systemic plasminogen activator inhibitor-1 (PAI-1) levels; elevated plasma PAI-1 levels are associated with endothelial dysfunction. ${ }^{38}$ Circulating PAI-1 levels are high in diabetics, contributing to the prothrombotic and proatherosclerotic changes. In addition, plasma PAI-1 levels are elevated in insulin resistance. ${ }^{39}$

On the other hand, cellular adhesion molecules play an important role in atherosclerosis, mediating margination, adhesion, and migration of circulating mononuclear cells from the blood stream to the extravascular compartment. ${ }^{40}$ They also activate mononuclear cells to release matrix MMPs, promoting plaque rupture and the initiation of acute coronary syndromes. ${ }^{40}$

In particular, sICAM-1 is linked to the subsequent incidence of coronary heart disease among healthy men and women. ${ }^{41,42}$ Two prospective cohort trials showed that levels of sICAM-1 are increased many years before a first myocardial infarction occurs, ${ }^{41}$ data on sVCAM-1 are not so clear. ${ }^{43}$ Regarding sE-selectin, instead, it confirmed to be a reliable marker and to be strongly linked to traditional cardiovascular risk factors. E-selectin mediates leukocyte rolling on the endothelium and platelet-leukocyte interaction; it is expressed in activated endothelial cells and acts as an adhesive reactant. On activation, sE-selectin is released into the circulation. Patients with myocardial infarction had increased levels of sE-selectin; moreover, sE-selectin levels are related to blood pressure. ${ }^{44}$

Matrix MMPs are proteolytic enzymes with the role of mediating changes in extracellular matrix. Humans have 24 matrix MMP genes. Matrix MMPs contribute to vascular remodeling and to the developing of atherosclerotic plaque. The activation of matrix MMPs modifies plaque architecture and may directly participate in the process of plaque rupture..$^{45}$ MMPs are extremely powerful proteolytic enzymes; thus, their biological actions are controlled by tissue inhibitor of MMPs. Among MMPs, MMP-2 and MMP-9 are the most important in vascular remodeling. ${ }^{46} \mathrm{MMP}-2$ and MMP-9 are $\mathrm{Zn}^{2+}$-dependent endopeptidases, synthesized and secreted in zymogen form. Increased MMP-2 and MMP-9 activities are associated with destruction of the elastic laminae of arteries and aneurysm formation in animals and humans. ${ }^{47}$ MMP-2 and MMP-9 are elevated in patients with obesity, ${ }^{48}$ 
hypertension, ${ }^{49}$ type 2 diabetes, ${ }^{50}$ and acute coronary syndrome. ${ }^{51-53}$ Moreover, plasma MMP-9 levels are a novel predictor of cardiovascular risk in patients with coronary artery disease and stroke..$^{54,55}$

\section{Conclusion}

Proatherogenic adhesion molecules (sICAM-1, sVCAM-1, and sE-selectin) and inflammatory cytokines (high-sensitivity CRP, IL-6, and TNF- $\alpha$ ) are elevated in type 2 diabetes mellitus. Their increased expression and release contribute to the accelerated atherogenesis typical of these patients. For these reasons, the early identification of high levels of these biomarkers will help to establish new strategies to reduce cardiovascular complications.

\section{Disclosure}

The authors have no relevant affiliations or financial involvement with any organization or entity with a financial interest in or financial conflict with the subject matter or materials discussed in the article. This includes employment, consultancies, honoraria, stock ownership or options, expert testimony, grants or patents received or pending, or royalties. No writing assistance was utilized in the production of this article. The authors report no other conflicts of interest in this work.

\section{References}

1. Wei M, Gaskill SP, Haffner SM, Stern MP. Effects of diabetes and level of glycemia on all-cause and cardiovascular mortality. The San Antonio Heart Study. Diabetes Care. 1998;21(7):1167-1172.

2. Haffner SM, Lehto S, Rönnemaa T, Pyörälä K, Laakso M. Mortality from coronary heart disease in subjects with type 2 diabetes and in nondiabetic subjects with and without prior myocardial infarction. $N$ Engl J Med. 1998;339(4):229-234.

3. Hegde SS, Mallesh P, Yeli SM, Gadad VM, GP M. Comparative angiographic profile in diabetic and non-diabetic patients with acute coronary syndrome. J Clin Diagn Res. 2014;8(9):MC07-MC10.

4. Tousoulis D, Kampoli AM, Stefanadis C. Diabetes mellitus and vascular endothelial dysfunction: current perspectives. Curr Vasc Pharmacol. 2012;10(1):19-32.

5. Kruth HS. Lipoprotein cholesterol and atherosclerosis. Curr Mol Med. 2001;1(6):633-653.

6. Croce K, Libby P. Intertwining of thrombosis and inflammation in atherosclerosis. Curr Opin Hematol. 2007;14(1):55-61.

7. Kampoli AM, Tousoulis D, Briasoulis A, Latsios G, Papageorgiou N, Stefanadis C. Potential pathogenic inflammatory mechanisms of endothelial dysfunction induced by type 2 diabetes mellitus. Curr Pharm Des. 2011;17(37):4147-4158.

8. Derosa G, D'Angelo A, Salvadeo SA, et al. Modification of vascular and inflammation biomarkers after OGTT in overweight healthy and diabetic subjects. Microvasc Res. 2010;79(2):144-149.

9. Derosa G, D'Angelo A, Salvadeo SA, et al. Oral glucose tolerance test effects on endothelial inflammation markers in healthy subjects and diabetic patients. Horm Metab Res. 2010;42(1):8-13.

10. Bansal TC, Guay AT, Jacobson J, Woods BO, Nesto RW. Incidence of metabolic syndrome and insulin resistance in a population with organic erectile dysfunction. $J$ Sex Med. 2005;2(1):96-103.
11. Zitzmann M. Testosterone deficiency, insulin resistance and the metabolic syndrome. Nat Rev Endocrinol. 2009;5(12):673-681.

12. Derosa G, Ferrari I, D'Angelo A, et al. Oral fat load effects on inflammation and endothelial stress markers in healthy subjects. Heart Vessels. 2009;24(3):204-210.

13. Derosa G, Ferrari I, D’Angelo A, et al. Effects of a standardized oral fat load on vascular remodeling markers in healthy subjects. Microvasc Res. 2010;80(1):110-115.

14. Davignon J, Ganz P. Role of endothelial dysfunction in atherosclerosis. Circulation. 2004;109(23 suppl 1):III27-III32.

15. Nygård O, Nordrehaug JE, Refsum H, Ueland PM, Farstad M, Vollset SE. Plasma homocysteine levels and mortality in patients with coronary artery disease. N Engl J Med. 1997;337(4):230-236.

16. Hossain GS, van Thienen JV, Werstuck GH, et al. TDAG51 is induced by homocysteine, promotes detachment-mediated programmed cell death, and contributes to the development of atherosclerosis in hyperhomocysteinemia. J Biol Chem. 2003;278(32):30317-30327.

17. Starkebaum G, Harlan JM. Endothelial cell injury due to coppercatalyzed hydrogen peroxide generation from homocysteine. J Clin Invest. 1986;77(4):1370-1376.

18. Lazzerini PE, Selvi E, Lorenzini S, et al. Homocysteine enhances cytokine production in cultured synoviocytes from rheumatoid arthritis patients. Clin Exp Rheumatol. 2006;24(4):387-393.

19. Dinneen SF, Gerstein HC. The association of microalbuminuria and mortality in non-insulin-dependent diabetes mellitus. A systematic overview of the literature. Arch Intern Med. 1997;157(13):1413-1418.

20. Jager A, Kostense PJ, Ruhé HG, et al. Microalbuminuria and peripheral arterial disease are independent predictors of cardiovascular and all-cause mortality, especially among hypertensive subjects: fiveyear follow-up of the Hoorn Study. Arterioscler Thromb Vasc Biol. 1999;19(3):617-624.

21. Stehouwer CD, Smulders YM. Microalbuminuria and risk for cardiovascular disease: analysis of potential mechanisms. J Am Soc Nephrol. 2006;17(8):2106-2111.

22. Hameed I, Masoodi SR, Mir SA, Nabi M, Ghazanfar K, Ganai BA. Type 2 diabetes mellitus: from a metabolic disorder to an inflammatory condition. World J Diabetes. 2015;6(4):598-612.

23. Popa C, Netea MG, van Riel PL, van der Meer JW, Stalenhoef AF. The role of TNF-alpha in chronic inflammatory conditions, intermediary metabolism, and cardiovascular risk. J Lipid Res. 2007;48(4):751-762.

24. Kuller LH, Tracy RP, Shaten J, Meilahn EN. Relation of C-reactive protein and coronary heart disease in the MRFIT nested case-control study. Multiple Risk Factor Intervention Trial. Am J Epidemiol. 1996;144(6):537-547.

25. Rock KL, Kono H. The inflammatory response to cell death. Annu Rev Pathol. 2008;3:99-126.

26. Rashidinejad H, Hosseini SM, Moazenzadeh M, et al. Relationship between serum level of high-sensitive C-reactive protein and extension of myocardial involvement in patients with acute myocardial infarction. Rom J Intern Med. 2012;50(3):211-215.

27. Aruoma OI. Free radicals, oxidative stress, and antioxidants in human health and disease. J Am Oil Chem Soc. 1998;75:199-212.

28. Fu X, Kassim SY, Parks WC, Heinecke JW. Hypochlorous acid oxygenates the cysteine switch domain of pro-matrilysin (MMP-7). A mechanism for matrix metalloproteinase activation and atherosclerotic plaque rupture by myeloperoxidase. J Biol Chem. 2001;276(44): 41279-41287.

29. Baldus S, Heitzer T, Eiserich JP, et al. Myeloperoxidase enhances nitric oxide catabolism during myocardial ischemia and reperfusion. Free Radic Biol Med. 2004;37(6):902-911.

30. Nauseef WM. Contributions of myeloperoxidase to proinflammatory events: more than an antimicrobial system. Int $J$ Hematol. 2001;74(2):125-133.

31. Papanicolaou DA, Wilder RL, Manolagas SC, Chrousos GP. The pathophysiologic roles of interleukin-6 in human disease. Ann Intern Med. 1998;128(2):127-137.

32. Heinrich PC, Castell JV, Andus T. Interleukin-6 and the acute phase response. Biochem J. 1990;265(3):621-636. 
33. Aharoni S, Aviram M, Fuhrman B. Paraoxonase 1 (PON1) reduces macrophage inflammatory responses. Atherosclerosis. 2013;228(2):353-361.

34. Abbott CA, Mackness MI, Kumar S, Boulton AJ, Durrington PN. Serum paraoxonase activity, concentration, and phenotype distribution in diabetes mellitus and its relationship to serum lipids and lipoproteins. Arterioscler Thromb Vasc Biol. 1995;15(11):1812-1818.

35. Ikeda $\mathrm{Y}$, Suehiro T, Inoue $\mathrm{M}$, et al. Serum paraoxonase activity and its relationship to diabetic complications in patients with non-insulindependent diabetes mellitus. Metabolism. 1998;47(5):598-602.

36. Singh RB, Mengi SA, Xu YJ, Arneja AS, Dhalla NS. Pathogenesis of atherosclerosis: a multifactorial process. Exp Clin Cardiol. 2002;7(1):40-53.

37. Tang Y, Jiang H, Bryan NS. Nitrite and nitrate: cardiovascular riskbenefit and metabolic effect. Curr Opin Lipidol. 2011;22(1):11-15.

38. Bouchie JL, Hansen H, Feener EP. Natriuretic factors and nitric oxide suppress plasminogen activator inhibitor-1 expression in vascular smooth muscle cells. Role of cGMP in the regulation of the plasminogen system. Arterioscler Thromb Vasc Biol. 1998;18(11): 1771-1779.

39. Pannacciulli N, De Mitrio V, Marino R, Giorgino R, De Pergola G. Effect of glucose tolerance status on PAI-1 plasma levels in overweight and obese subjects. Obes Res. 2002;10(8):717-725.

40. Ross R. Atherosclerosis - an inflammatory disease. $N$ Engl J Med. 1999;340(2):115-126.

41. Ridker PM, Hennekens CH, Buring JE, Rifai N. C-reactive protein and other markers of inflammation in the prediction of cardiovascular disease in women. $N$ Engl J Med. 2000;342(12):836-843.

42. Porsch-Oezçueruemez M, Kunz D, Kloer HU, Luley C. Evaluation of serum levels of solubilized adhesion molecules and cytokine receptors in coronary heart disease. J Am Coll Cardiol. 1999;34(7):1995-2001.

43. de Lemos JA, Hennekens CH, Ridker PM. Plasma concentration of soluble vascular cell adhesion molecule-1 and subsequent cardiovascular risk. J Am Coll Cardiol. 2000;36(2):423-426.
44. Thorand B, Baumert J, Döring A, et al. Association of cardiovascular risk factors with markers of endothelial dysfunction in middle-aged men and women. Results from the MONICA/KORA Augsburg Study. Thromb Haemost. 2006;95(1):134-141.

45. Liu P, Sun M, Sader S. Matrix metalloproteinases in cardiovascular disease. Can J Cardiol. 2006;22(suppl B):25B-30B.

46. Gibbons GH, Dzau VJ. The emerging concept of vascular remodeling. N Engl J Med. 1994;330(20):1431-1438.

47. Longo GM, Xiong W, Greiner TC, Zhao Y, Fiotti N, Baxter BT. Matrix metalloproteinases 2 and 9 work in concert to produce aortic aneurysms. J Clin Invest. 2002;110(5):625-632.

48. Derosa G, Ferrari I, D'Angelo A, et al. Matrix metalloproteinase-2 and -9 levels in obese patients. Endothelium. 2008;15(4):219-224.

49. Derosa G, D'Angelo A, Ciccarelli L, et al. Matrix metalloproteinase-2, -9 , and tissue inhibitor of metalloproteinase- 1 in patients with hypertension. Endothelium. 2006;13(3):227-231.

50. Derosa G, D’Angelo A, Tinelli C, et al. Evaluation of metalloproteinase 2 and 9 levels and their inhibitors in diabetic and healthy subjects. Diabetes Metab. 2007;33(2):129-134.

51. Derosa G, Cicero AF, Scalise F, et al. Metalloproteinase-2 and -9 in diabetic and nondiabetic subjects during acute coronary syndromes. Endothelium. 2007;14(1):45-51.

52. Derosa G, Cicero AF, Scalise F, et al. Metalloproteinases in diabetics and nondiabetics during acute coronary syndromes and after 3 months. Endothelium. 2007;14(4-5):175-183.

53. Derosa G, D'Angelo A, Scalise F, et al. Comparison between metalloproteinases-2 and -9 in healthy subjects, diabetics, and subjects with acute coronary syndrome. Heart Vessels. 2007;22(6):361-370.

54. Blankenberg S, Rupprecht HJ, Poirier O, et al. Plasma concentrations and genetic variation of matrix metalloproteinase 9 and prognosis of patients with cardiovascular disease. Circulation. 2003;107(12):1579-1585.

55. Montaner J, Molina CA, Monasterio J, et al. Matrix metalloproteinase-9 pretreatment levels predicts intracranial hemorrhagic complications after thrombolysis in human stroke. Circulation. 2003;107(4):598-603.
Vascular Health and Risk Management

\section{Publish your work in this journal}

Vascular Health and Risk Management is an international, peerreviewed journal of therapeutics and risk management, focusing on concise rapid reporting of clinical studies on the processes involved in the maintenance of vascular health; the monitoring, prevention and treatment of vascular disease and its sequelae; and the involvement of

\section{Dovepress}

metabolic disorders, particularly diabetes. This journal is indexed on PubMed Central and MedLine. The manuscript management system is completely online and includes a very quick and fair peer-review system, which is all easy to use. Visit http://www.dovepress.com/ testimonials.php to read real quotes from published authors. 